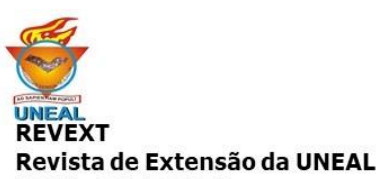

Revista de Extens

Ano 6, Vol. 6 (2), no 2. 2021, julho/dezembro de 2021. https://doi.org/10.48179/revext.v6i2.183

\title{
O ensino de ciências e a peça teatral "heróis da ciência": olhares dos estudantes com necessidades educacionais especiais
}

\author{
Anderson Gomes dos Santos ${ }^{1}$ \\ Samara Cavalcanti da Silva Melo \\ ${ }^{1}$ Pós-graduando em Educação Inclusiva pela Universidade Estadual de Alagoas. Graduado em Pedagogia pela \\ Universidade Estadual de Alagoas. E-mail: anderson_pedagogia@hotmail.com \\ ${ }^{2}$ Professora dos cursos de licenciatura da Universidade Estadual de Alagoas, graduada em Pedagogia - pela \\ Universidade Federal Rural de Pernambuco e Mestra em Educação pela Universidade Federal de Pernambuco \\ (UFPE).. E-mail: sammara_c_silva@hotmail.com
}

Resumo - O ensino de Ciências da Natureza na educação básica é fundamental no contexto da compreensão do mundo e dos fenômenos naturais. Nesse sentido, o ensino das Ciências busca proporcionar a efetiva formação crítica dos cidadãos, possibilitando a construção de evidências, elaboração de argumentos, na contra-argumentação, elaboração de teorias alternativas, e para a refutação. Nesse contexto, a presente pesquisa buscou investigar: como a peça teatral "HERÓIS DA CIÊNCIA", contribui ou limita a compreensão de conteúdos de Ciências da Natureza (Química), por estudantes com Necessidades Educacionais Especiais (NEE). O objetivo da pesquisa foi analisar as contribuições e limites da peça teatral "HERÓIS DA CIÊNCIA", na compreensão de conteúdos de Ciências da Natureza (Química), por estudantes com Necessidades Educacionais Especiais. Para tanto, a pesquisa foi qualitativa, com aplicação de questionários antes e após a peça de teatro científico, realizada no mês de outubro de 2019, em uma escola pública estadual, localizada em Palmeira dos Índios - AL. Diante dos resultados apresentados, foi visto que os estudantes reconhecem a necessidade de atividades diversificadas para o processo de ensino e aprendizagem de Ciências, e, especificamente da tabela periódica, além de possibilitar, por meio da peça a ampliação das aprendizagens dos mesmos sobre a química.

Palavras-chave: Ensino de Ciências. Arte. Teatro. Ensino Médio.

Abstract - Teaching natural sciences in basic education is fundamental in the context of understanding the world and natural phenomena. In this sense, the teaching of Science seeks to providencie a criticam formation of citizens, enabling the construction of evidence, the elaboration of counter-argumentation, and the elaboration of alternative theories. In this sense, the present research sought to investigate how the play:" Heroes of Science" contributes or limits the understanding of natural sciences ( Chemistry) buy students with special needs ( SEN). Therefore, the research was qualitative, applying questionnaires before and after the science theater piece; held on October 2019, in a state public school, located in the Palmeira dos Índios city/ AL. Against the results presented, students recognize the necessity of diversifield activities for science teaching and learning, and, specifically, periodic table, beyond possible through theater, expanding students learning about chemical teaching.

Keywords: Science Teaching. Art. Theater. School. 


\section{INTRODUÇÃO}

A Educação Básica deve proporcionar, dentre outras aprendizagens, a compreensão dos fenômenos físicos e naturais. E, especialmente, a fim de contribuir com a formação dos cidadãos críticos e reflexivos sobre os fenômenos da natureza, o ensino de Ciências deve proporcionar a investigação com base nas evidências, elaboração de argumentos, na contra argumentação, elaboração de teorias alternativas, e para a refutação.

Nesse contexto, a Educação Básica assume um espaço de destaque nas ações específicas de formação dos estudantes e na construção de práticas educacionais, no qual se torna essencial que projetos pedagógicos tenham articulação dos conhecimentos das diferentes áreas do conhecimento para a formação do sujeito. E o ensino de Ciências com a Arte pode potencializar, significativamente, o aprendizado dos estudantes.

A articulação entre a Arte e a Ciência não é recente, pois, pesquisas sinalizam a possibilidade de interligação entre as áreas e, especialmente, a possibilidade de aprender Ciência através da Arte (CACAHPUZ, 2014);( RANGEL, 2014). Nesse sentido, a presente pesquisa buscou investigar: como a peça teatral "HERÓIS DA CIÊNCIA", contribui ou limita a compreensão de conteúdos de Ciências da Natureza (Química), por estudantes com necessidades Educacionais Especiais (NEE)?

Assim, objetivo geral da pesquisa foi analisar as contribuições e limites da peça teatral "HERÓIS DA CIÊNCIA”, na compreensão de conteúdos de Ciências da Natureza (Química), por estudantes com NEE. E, como objetivos específicos: conhecer as contribuições e os limites da peça teatral "HERÓIS DA CIÊNCIA", na formação de conteúdos de Ciências da Natureza (Química); identificar a compreensão da peça teatral "HERÓIS DA CIÊNCIA" na perspectiva dos estudantes com NEE; e, ainda, conhecer a compreensão dos estudantes com NEE sobre a ciência e o ensino na escola por meio da peça teatral "HERÓIS DA CIÊNCIA".

$\mathrm{O}$ artigo segue estruturado em quatro seções. A primeira discute acerca do ensino de Ciências na educação básica, com ênfase na química e, ainda, as possibilidades de ensino por meio da Arte. Já a segunda apresenta o tipo de pesquisa, instrumentos de pesquisa, universo, período de pesquisa e o tipo de análise realizada. Na terceira seção, os resultados da pesquisa 


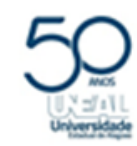

Ano 6, Vol. 6 (2), no 2. 2021, julho/dezembro de 2021.

https://doi.org/10.48179/revext.v6i2.183

são apresentados e analisados. E, por fim, na última seção, as considerações finais e as referências citadas.

\section{ENSINO DE CIÊNCIAS E O TEATRO CIENTÍfICO: CAMINHO DE POSSIBILIDADES NA EDUCAÇÃO BÁSICA}

Para tratar sobre o Ensino de Ciências da Natureza, com ênfase na química, torna-se essencial compreender que historicamente a inserção do ensino das Ciências se deu a partir de março de 1950, quando houve a ênfase na formação de investigadores científicos, a fim de impulsionar o desenvolvimento científico industrial e tecnológico no país. Contudo, no decorrer das décadas, diferentes concepções de ensinar, aprender e objetivos deste ensino foram sofrendo alterações, com base no contexto histórico (KRASILCHIK, 2012). Nesse mesmo período, o campo educacional brasileiro é demarcado pelo curso ginasial com foco na formação de universitários. Na época, a preocupação principal não era a formação de especialistas, além de haver pouca ênfase nas áreas Científicas, pois "o latim tinha preponderância sobre as disciplinas científicas, cuja carga horária era de três aulas semanais nas terceiras e quartas séries do curso ginasial. Física, Química e História Natural apareciam apenas no currículo do curso colegial" (KRASILCHIK, 2012, p. 19). Em meados de 1980, surge um novo desafio para os educadores de todos os graus de ensino: tornar o ensino de química articulado com as necessidades e interesses de boa parte dos alunos nas escolas do Ensino Fundamental e Médio. Especialmente, diante da regulamentação da legislação sobre o ensino de Ciências em todas as "séries" do antigo ginasial (BRASIL, 1971).

Contudo, mesmo diante da obrigatoriedade prevista em legislação, pesquisas sinalizam as dificuldades na compreensão dos assuntos. Adicionalmente, os desafios perpassam o ensino que nem sempre está contextualizado com a realidade e cotidiano do estudante, bem como a fragmentação das áreas de conhecimento que repercutem na falta de interesse e no não aprendizado da Química. Com implicações diretas no processo de ensino e aprendizagem, além da ausência da interdisciplinaridade e contextualização (NUNES e ADORNI, 2010), de acordo com Pontes, 


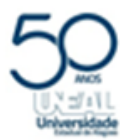

Ano 6, Vol. 6 (2), no 2. 2021, julho/dezembro de 2021.

https://doi.org/10.48179/revext.v6i2.183

conteúdos são trabalhados de forma descontextualizada, tornando-se distantes da realidade e difíceis de compreender, não despertando o interesse e a motivação dos alunos. Além disso, os professores de química demonstram dificuldades em relacionar os conteúdos científicos com eventos da vida cotidiana, priorizando a reprodução do conhecimento, a cópia e a memorização, esquecendo, muitas vezes, de associar a teoria com a prática. (PONTES et. al., 2008, p. 01).

$\mathrm{Na}$ contemporaneidade, o Ensino de Ciências da Natureza (Química) visa proporcionar a compreensão dos fenômenos e conteúdos que estão no nosso cotidiano. De acordo com Chassot (2003, p. 92) “dentre as muitas ciências, a química, por exemplo, é aquela que estuda como as substâncias se transformam e são transformadas em outras substâncias". Nesse sentido, a química proporciona a capacidade de pensar de forma lógica, observar, experimentar, buscar soluções e explicações, compreender e refletir de forma crítica a realidade.

Para tanto, a Base Nacional Comum Curricular (BRASIL, 2018) regulamenta que, dentre outras competências específicas, a Educação Básica precisa promover a investigação e a interdisciplinaridade no trabalho pedagógico. E, ainda, prevê que é possível observar que ela faz um apontamento para essa relação do saber científico com outras formas de compreensão, por exemplo, através da arte. Segundo o documento:

A contextualização social, histórica e cultural da ciência e da tecnologia é fundamental para que elas sejam compreendidas como empreendimentos humanos e sociais. Na BNCC, portanto, propõe-se também discutir o papel do conhecimento científico e tecnológico na organização social, nas questões ambientais, na saúde humana e na formação cultural, ou seja, analisar as relações entre ciência, tecnologia, sociedade e ambiente (BRASIL, 2018, p. 549).

Assim, o trabalho docente deve proporcionar essas possibilidades de interdisciplinaridade com a Arte, a partir da percepção de que o teatro pode contribuir no ensino-aprendizagem de estudantes do Ensino Médio. É amplamente possível aprender Ciências através da Arte, essas competências gerais estão de forma ampla na formação do estudante no decorrer da Educação Básica. E, aproximação das áreas foi algo significativo, pois,

Historicamente, as aproximações entre Arte e Ciência não são novas. O paradigma desta aproximação remonta à obra de Leonardo da Vinci (século XVI), como paradigma do homem renascentista, transversal nos seus conhecimentos e referência histórica fundamental desta proposta de conhecimento transversal (CACHAPUZ, 2014, p. 95). 


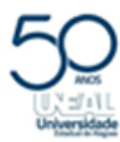

Ano 6, Vol. 6 (2), no 2. 2021, julho/dezembro de 2021.

https://doi.org/10.48179/revext.v6i2.183

Nesse sentido, aprender a Ciência com a Arte favorece o desenvolvimento da leitura de mundo, da solidariedade e a cooperação que o tornará capaz de conviver com as diferenças no conjunto social. Além de compartilhar com a comunidade na construção de uma sociedade que possa compreender outras possibilidades de aprendizagem.

A Arte, e especialmente o teatro, constitui uma linguagem artística que proporciona diversos sentimentos nos participantes da peça e na plateia. E, especialmente, a relação entre a Arte e a Ciência se dá no século XX, a partir da dramaturgia Vida de Galileu (1956), de Bertold Brecht, bem como os o Caso Oppenheimer (1964) de Heinar Kipphardt e os Físicos (1960), de Friedrich Dürremant (VENTURA et. al., 2018). O teatro científico permeia assuntos da Ciência, com temáticas específicas e eventos que ocorrem anualmente no Brasil.

O teatro científico une Ciência com aspectos teatrais como mímica, interpretação, mudanças de vozes e adereços cênicos com um forte apelo visual. É importante ressaltar que, embora seja uma atividade lúdica que traz elementos artísticos em sua essência, existe uma preocupação constante em inserir conceitos corretos, atuais e relevantes para a Ciência, Tecnologia e Sociedade. Somente com o equilíbrio entre Arte e Ciência, de maneira divertida e pedagógica, é que se estará atingindo os objetivos do teatro científico, que é despertar nos alunos o interesse pela Ciência e seus desdobramentos. Neste gênero, a plateia geralmente não é formada por um público genérico como no teatro convencional, mas sim por estudantes, acadêmicos e educadores. (VENTURA et. al. 2018, p. 827):

Assim, o teatro científico pode proporcionar e despertar a compreensão dos estudantes sobre as temáticas abordadas na peça. Além de suscitar nos estudantes o interesse na Ciência. Assim, a argumentação se faz necessária tanto para o professor, quanto para o estudante que terá como visualização uma nova forma de aprender, principalmente na contribuição que a arte pode proporcionar ao seu conhecimento com relação às Ciências. Segundo Rangel

\footnotetext{
Associar arte e ciência na construção de saberes é o mesmo que associar razão e emoção, objetividade e sensibilidade, lógica, intuição e criação. Dessa forma, superam-se fragmentações e rupturas, para que se possa compreender, de modo mais abrangente, o mundo e as relações dos homens entre si e com a natureza (RANGEL, 2014, p. 74):
}

Para tanto, os conteúdos de Ciências da Natureza (Química) que serão trabalhados devem ser contextualizados e com base na situação investigativo/reflexiva. Esse processo de compreensão será apresentado para os alunos com Necessidades Educacionais Especiais (NEE), a partir do teatro. Com isso, criamos novas possibilidades de ensino e aprendizagem, 


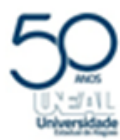

Ano 6, Vol. 6 (2), no 2. 2021, julho/dezembro de 2021.

https://doi.org/10.48179/revext.v6i2.183

com o direcionamento da prática pedagógica para todos os estudantes, a fim de promover o acesso ao conhecimento científico e a escola inclusiva. De acordo com Jorgensen (1999. p. 262):

Uma escola só é realmente inclusiva se cada aluno, incluindo aqueles com deficiências, puder participar de momentos de aprendizagem e se esforçar para atingir resultados desafiadores. Com relação aos alunos com deficiências importantes, a estrutura de planejamento do currículo deve considerar suas necessidades de aprendizagem individual, concentrando a atenção dos professores no apoio e nas adaptações necessárias para cada aluno participar plenamente da unidade e atingir seus objetivos de aprendizagem.

Nesse contexto, o uso do teatro científico para aprendizagem de conteúdos da química será problematizado, a fim de proporcionar a compreensão dos estudantes com NEE. Para tanto, a instituição educacional precisa promover situações investigativas, motivadoras e que despertem nos estudantes a necessidade de aprender Ciência.

\section{O TEATRO CIENTÍFICO: PRIMEIRAS APROXIMAÇÕES COM A PEÇA TEATRAL}

O grupo teatral "Os loucos também amam" criou a peça "Heróis da Ciência" que se constitui em uma liga de "Super Heróis/ Heroínas" que buscam proteger as Ciências, a literatura, museus e as comunidades indígenas. A luta dos heróis é contra os vilões que querem destruir o planeta. A proposta do espetáculo é consolidar que as Ciências e outros conhecimentos podem ser vivenciadas com Teatro em espaços formais e não formais. E ainda, e apresentar como os conhecimentos produzidos na escola devem ser priorizados para o desenvolvimento educacional e cultural da sociedade, e isso precisa estar claro em todo território. O Espetáculo foi construído de forma colaborativa com os atores e atrizes que escreveram e pesquisaram sobre seus personagens e personalidades.

A referida pesquisa caracterizou-se por analisar como o espetáculo teatral Heróis da Ciência contribui no ensino e aprendizagem da química no contexto da tabela periódica (elementos químicos), de estudantes do Ensino Médio Integral da Rede Estadual de Ensino de Palmeira dos Índios - AL, com Necessidades Educacionais Especiais. Principalmente, a identificação, contribuição e os limites do espetáculo "Heróis da Ciência" na aprendizagem da relação dos diferentes elementos químicos. 


\title{
O CAMINHO METODOLÓGICO
}

O processo metodológico consiste em uma pesquisa de campo, com abordagem qualitativa, com intuito de analisar as contribuições e limites da peça teatral "HERÓIS DA CIÊNCIA", na compreensão de conteúdos de Ciências da Natureza (Química), por estudantes com NEE. De acordo com Minayo (2008), a pesquisa qualitativa investiga as questões particulares, estudando a realidade que perpassa os sentidos, compreensões e valores da temática em estudo. Para a autora:

\begin{abstract}
A pesquisa qualitativa responde à questões muito particulares. Ela se ocupa, nas $\mathrm{Ci}$ ências Sociais, com um nível de realidade que não pode ou não deveria ser quantificado. [...] universo dos significados, dos motivos, das aspirações, das crenças, dos valores e das atitudes (p. 21, grifo nosso).
\end{abstract}

Nesse sentido, a pesquisa de contexto qualitativo é fundamental em Escolas Públicas da Educação Básica já que possibilitam propostas diferenciadas e inovação. A pesquisa foi realizada no mês de outubro de 2019, com aplicação de questionário para toda a plateia que assistiu à peça teatral, totalizando 45 participantes. Mas, na presente discussão e análise serão considerados, apenas, os oito questionários respondidos por estudantes com NEE.

Compreender os processos metodológicos e a importância de cada instrumento é fundamental, por isso, nesta pesquisa o questionário consolida a percepção dos estudantes com NEE sobre a peça e o ensino das Ciências da Natureza. Segundo Gil, 1999 p. 128-129), o uso do questionário na pesquisa:

a) possibilita atingir grande número de pessoas, mesmo que estejam dispersas numa área geográfica muito extensa, já que o questionário pode ser enviado pelo correio; b) implica menores gastos com pessoal, posto que o questionário não exige o treinamento dos pesquisadores; c) garante o anonimato das respostas; d) permite que as pessoas o respondam no momento em que julgarem mais conveniente; e) não expõe os pesquisadores à influência das opiniões e do aspecto pessoal do entrevistado.

Assim, os questionários foram aplicados antes e após o espetáculo. O primeiro questionário, é composto por 08 (oito) perguntas e o segundo com 06 (seis). Os alunos pesquisados foram: 03 (sete) do sexo masculino e 01 (um) do sexo feminino, todos vinculados 


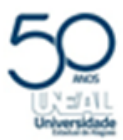

Ano 6, Vol. 6 (2), no 2. 2021, julho/dezembro de 2021. https://doi.org/10.48179/revext.v6i2.183 ao Ensino Médio. Por questões éticas, o nome da instituição e participantes não serão divulgados. Serão utilizados pseudônimos para a identificação dos estudantes, a saber: Polônio, Chumbo, Cálcio e Sódio. E, ainda, foram utilizados o Termo de Consentimento Livre e Esclarecido com os participantes da pesquisa. O critério de escolha do universo e dos participantes foram a atuação direta na instituição e, ainda, o interesse em participar da pesquisa.

Para responder as questões norteadoras e alcançar os objetivos elencados, construímos o corpus empírico com base nos questionários e a análise de conteúdo com base em Bardin (2011). Para a autora, a análise de conteúdo se caracteriza como:

\footnotetext{
Um conjunto de técnicas de análise das comunicações visando obter, por procedimentos, sistemáticos e objetivos de descrição do conteúdo das mensagens, indicadores (quantitativos ou não) que permitam a inferência de conhecimentos relativos às condições de produção/recepção (variáveis inferidas) destas mensagens (42).
}

Nesse contexto, a análise de conteúdo proporciona a descrição dos conteúdos expressos nas mensagens apresentadas no questionário acerca da peça teatral e a aprendizagem de conteúdos de Ciências com estudantes com NEE.

\section{A TABELA PERIÓDICA E AS AULAS DE CIÊNCIAS}

O ensino da tabela periódica nos anos finais do Ensino Fundamental e Ensino Médio é de suma importância para a aprendizagem dos conceitos científicos dos elementos. Além de um contexto de abstração, os estudantes precisam compreender que o estudo da tabela periódica é importante para o seu cotidiano. Para o Ensino Médio essa necessidade é pertinente. A peça teatral é uma ação que pode exemplificar e explicar conceitos científicos. A Base Nacional Comum Curricular coloca isso em discussão em sua última versão:

Na área de Ciências da Natureza, os conhecimentos conceituais são sistematizados em leis, teorias e modelos. A elaboração, a interpretação e a aplicação de modelos explicativos para fenômenos naturais e sistemas tecnológicos são aspectos fundamentais do fazer científico, bem como a identificação de regularidades, invariantes e transformações. Portanto, no Ensino Médio, o desenvolvimento do pensamento científico envolve aprendizagens específicas, com vistas a sua aplicação em contextos diversos (BRASIL, 2018, p. 550). 


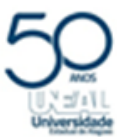

Ano 6, Vol. 6 (2), no 2. 2021, julho/dezembro de 2021.

https://doi.org/10.48179/revext.v6i2.183

O questionário 01 (um) apresenta os conceitos científicos que os alunos com necessidades educacionais presentes na plateia conseguiram consolidar nas aulas de Ciências no Ensino Médio.

A Tabela Periódica é um arranjo que permite não somente compreender a organização dos elementos, mas também formar estruturas e fazer previsões quanto ao comportamento e formação de diversificados tipos de moléculas. É considerada uma das maiores evoluções relacionadas ao estudo da Química, que passou por diversas transformações significativa para a evolução da Química como ciência. (LEITE, 2015, p. 16).

É importante observar que cada aluno respondeu a partir da relação que estabeleceu com as disciplinas que trabalham conceitos científicos no âmbito escolar. Contudo, é preciso entender o quanto que é importante o ensino desses conceitos (tabela periódica utilizando o teatro como ferramenta).

QUADRO 01 - Antes da Peça -Estudantes com baixa visão (Polônio e Chumbo).

\begin{tabular}{|c|c|c|}
\hline Perguntas & Respostas - Polônio & Respostas - Chumbo \\
\hline $\begin{array}{l}\text { 1) O que aprendeu sobre a tabela periódica } \\
\text { na Escola? }\end{array}$ & $\begin{array}{l}\mathrm{O} \text { básico, não foi algo muito } \\
\text { aprofundado. }\end{array}$ & $\begin{array}{l}\text { Aprendi sobre os elementos, } \\
\text { benefícios e como lidar com os } \\
\text { sintomas. }\end{array}$ \\
\hline $\begin{array}{l}\text { 2) Qual a importância de estudar e } \\
\text { aprender sobre a tabela periódica para sua } \\
\text { vida? }\end{array}$ & Sim, mas ética e moral também. & $\begin{array}{l}\text { Muito importante para saber lidar } \\
\text { com os elementos. }\end{array}$ \\
\hline $\begin{array}{l}\text { 3) Você teve experiência de aprender } \\
\text { ciências com arte na escola? }\end{array}$ & $\begin{array}{l}\text { Não. Seria uma forma até mais } \\
\text { divertida de aprender. }\end{array}$ & Sim, com um filme. \\
\hline $\begin{array}{l}\text { 4) Como são as aulas de ciências } \\
\text { (Química, Física e Biologia)? }\end{array}$ & $\begin{array}{l}\text { Muitas são teorias para responder } \\
\text { exercícios. }\end{array}$ & $\begin{array}{l}\text { Estudo do livro e resolver os } \\
\text { exercícios. }\end{array}$ \\
\hline $\begin{array}{l}\text { 5) Você acha possível aprender ciências } \\
\text { com teatro? }\end{array}$ & $\begin{array}{l}\text { Sim, essa forma conseguimos } \\
\text { compreender de outra forma. }\end{array}$ & Sim, bem possível. \\
\hline $\begin{array}{l}\text { 6) Quais desses elementos você já ouviu } \\
\text { falar? } \\
\text { Chumbo; Alumínio; Oxigênio; } \\
\text { Hidrogênio; Cálcio; Ferro; Mercúrio; } \\
\text { Rubídio; Nitrogênio, Plutônio e Hélio }\end{array}$ & De todos. & Não muitos \\
\hline $\begin{array}{l}\text { 7) Quais elementos da tabela periódica } \\
\text { você lembra as propriedades? }\end{array}$ & $\begin{array}{l}\text { O básico como seus reagentes } \\
\text { principalmente onde é encontrado em } \\
\text { nosso cotidiano. }\end{array}$ & Alumínio e Hélio. \\
\hline
\end{tabular}


Ano 6, Vol. 6 (2), no 2. 2021, julho/dezembro de 2021.

https://doi.org/10.48179/revext.v6i2.183

\begin{tabular}{l|l|l|} 
8) Como as aulas de ciências poderiam ser & Sim, a pintura e o desenho pode ser & $\begin{array}{l}\text { Acho que com música seria uma } \\
\text { possibilidade. } \\
\text { mais atrativas? Aponte outras } \\
\text { possibilidades para aprender ciências. }\end{array}$ \\
uma de outras formas.
\end{tabular}

(Fonte: questionários).

QUADRO 2 - Antes da Peça -Os estudantes com deficiência intelectual (Cálcio e Sódio).

\begin{tabular}{|c|c|c|}
\hline Perguntas & Respostas - Cálcio & Respostas - Sódio \\
\hline $\begin{array}{l}\text { 1) O que aprendeu sobre a tabela periódica } \\
\text { na Escola? }\end{array}$ & Família, número e massa. & $\begin{array}{l}\text { Metais e ametais, gases que não } \\
\text { precisam se misturar com outros } \\
\text { elementos. }\end{array}$ \\
\hline $\begin{array}{l}\text { 2) Qual a importância de estudar e } \\
\text { aprender sobre a tabela periódica para sua } \\
\text { vida? }\end{array}$ & $\begin{array}{l}\text { Sim, pois nos deparamos com cada } \\
\text { elemento em nossa vida. }\end{array}$ & $\begin{array}{l}\text { Sim, para tomar cuidado com alguns } \\
\text { elementos. }\end{array}$ \\
\hline $\begin{array}{l}\text { 3) Você teve experiência de aprender } \\
\text { ciências com arte na escola? }\end{array}$ & Sim. & Não essa peça é a primeira. \\
\hline $\begin{array}{l}\text { 4) Como são as aulas de ciências } \\
\text { (Química, Física e Biologia)? }\end{array}$ & $\begin{array}{l}\text { Às vezes a professora de biologia faz } \\
\text { maquetes. }\end{array}$ & Resolvendo situações químicas. \\
\hline $\begin{array}{l}\text { 5)Você acha possível aprender ciências } \\
\text { com teatro? }\end{array}$ & Sim. & Sim, acho legal. \\
\hline $\begin{array}{l}\text { 6) Quais desses elementos você já ouviu } \\
\text { falar? } \\
\text { Chumbo; Alumínio; Oxigênio; } \\
\text { Hidrogênio; Cálcio; Ferro; Mercúrio; } \\
\text { Rubídio; Nitrogênio, Plutônio e Hélio. }\end{array}$ & Todos & De todos eles. \\
\hline $\begin{array}{l}\text { 7) Quais elementos da tabela periódica } \\
\text { você lembra as propriedades? }\end{array}$ & Mercúrio e Ferro. & Plutônio e o Chumbo \\
\hline $\begin{array}{l}\text { 8) Como as aulas de ciências poderiam ser } \\
\text { mais atrativas? Aponte outras } \\
\text { possibilidades para aprender ciências. }\end{array}$ & $\begin{array}{l}\text { Não pensei sobre isso ainda, mas o } \\
\text { teatro seria uma forma. }\end{array}$ & Seria com paródias e desenhos. \\
\hline
\end{tabular}

(Fonte: questionários). 


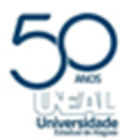

Ano 6, Vol. 6 (2), no 2. 2021, julho/dezembro de 2021.

\title{
A CIÊNCIA E A ARTE
}

\section{https://doi.org/10.48179/revext.v6i2.183}

A Ciência e a Arte tem inúmeras aproximações. É possível no contexto escolar tecer diversas propostas pedagógicas que utilizem não somente o teatro. Claro que se faz necessário estudo e uma ação interdisciplinar efetiva para que possam relacionar-se respeitando o conceito específico de cada disciplina. Vejam a comparação entre a atividade cientifica e a música:

\begin{abstract}
A atividade científica pode ser comparada à atividade de um músico que compõe para uma orquestra. Ele deve coordenar uma série de instrumentos para que soem de forma harmoniosa. Um som nunca é certo ou errado, apenas adequado ou não, dada a intenção no momento da composição. Os instrumentos têm suas especificidades, mas, há um objetivo que os une (a música em apresentação). O sentimento do compositor necessita ser interpretado. O som produzido não é inerte, pois afeta sentimentos, processos humanos, pode mudar uma história (VOLPATO, 2013, p. 29).
\end{abstract}

É claro que é necessário um processo formativo para professores e alunos. Essas comparações e aproximações são verdadeiras e podem ser contínuas no processo escolar, no qual cientistas e artistas lidam muitas vezes com os mesmos conceitos e evidências. No entanto, é necessário estudo e revisão desses conceitos.

Sobre a peça teatral "HERÓIS DA CIÊNCIA", a mesma foi apresentada após o texto, o cenário e os figurinos serem produzidos elou organizados pelos próprios alunos com orientação e mediações do professor, depois do estudo e compreensão dos conteúdos inerentes aos elementos da tabela periódica. Há efeito de luzes e sons, os figurinos têm cores de acordo com características dos elementos apresentados e são utilizadas ferramentas confeccionadas de acordo com funções dos elementos representando as armas, bem como também são utilizados objetos e ou recursos naturais que se envolvam nos conteúdos apresentados, como bacia de alumínio, verduras e frascos com líquidos representando elementos inflamáveis.

Durante a apresentação, os alunos que representam os elementos nocivos à saúde de pessoas e animais são os vilões (como mercúrio e chumbo), que tentam atingir de várias formas os elementos essenciais a vida. Os elementos essenciais à vida, os alunos representam suas composições e funções através de cena envolvendo humor, ação e enfrentamento de situações problema, sendo os combatentes do mal, os heróis que demonstram o poder dos elementos, como cálcio, hidrogênio e oxigênio. No desfecho, os Heróis demonstram ter maior 


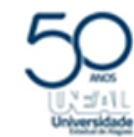

Ano 6, Vol. 6 (2), no 2. 2021, julho/dezembro de 2021. https://doi.org/10.48179/revext.v6i2.183 força sobre as reações químicas ocorridas a partir das substâncias e efeitos causados pelos vilões.

Os quadros 3 e 4 apresentam a observação e a percepção dos alunos referentes à peça apresentada e também aos conceitos anteriormente contextualizados pelos mesmos no contexto escolar.

QUADRO 3 - Posterior à peça - Estudantes com baixa visão (Polônio e Chumbo).

\begin{tabular}{|c|c|c|}
\hline Perguntas & Respostas - Polônio & Respostas - Chumbo \\
\hline $\begin{array}{l}\text { 1) Você gostou da apresentação? } \\
\text { Conseguiu aprender algo? Escreva um } \\
\text { pouco sobre isso. }\end{array}$ & $\begin{array}{l}\text { A função dos elementos, seus poderes } \\
\text { e reagentes. }\end{array}$ & $\begin{array}{l}\text { Sim, principalmente o bem e o mal } \\
\text { que cada elemento faz. }\end{array}$ \\
\hline $\begin{array}{l}\text { 2) O que mais chamou sua atenção na } \\
\text { apresentação? }\end{array}$ & Tudo, mas gostei dos poderes. & $\begin{array}{l}\text { A capacidade do hélio de "afinar" a } \\
\text { voz e o cálcio importante para o } \\
\text { desenvolvimento dos ossos. }\end{array}$ \\
\hline $\begin{array}{l}\text { 3) Quais dos elementos apresentados na } \\
\text { peça são fundamentais para sua vida? }\end{array}$ & Oxigênio e Cálcio. & Alumínio, Cálcio, Oxigênio. \\
\hline $\begin{array}{l}\text { 4) O que você lembra do espetáculo? Fale } \\
\text { sobre o que lembra dos elementos } \\
\text { apresentados na peça. }\end{array}$ & $\begin{array}{l}\text { Da forma de combater o chumbo e } \\
\text { mercúrio. }\end{array}$ & $\begin{array}{l}\text { Da forma de como lidar com cada } \\
\text { elemento. }\end{array}$ \\
\hline $\begin{array}{l}\text { 5) Quais desses elementos apresentados na } \\
\text { peça você lembra mais? Quais dos } \\
\text { elementos você mais gostou? Justifique } \\
\text { sua resposta. }\end{array}$ & $\begin{array}{l}\text { Nitrogênio, Hidrogênio, Mercúrio e } \\
\text { Cálcio. }\end{array}$ & $\begin{array}{l}\text { Alumínio, Cromo, Cobre, Hélio e } \\
\text { Cálcio. }\end{array}$ \\
\hline $\begin{array}{l}\text { 6) O ensino de ciências com teatro é } \\
\text { importante para aprender ciências? Você } \\
\text { consegue ver sentido nessa prática? }\end{array}$ & $\begin{array}{l}\text { Sim, pois a várias outras formas que } \\
\text { podemos usar para aprender, tem } \\
\text { sentido. }\end{array}$ & $\begin{array}{l}\text { Sim, assim saberíamos como lidar } \\
\text { com os sintomas de todos os } \\
\text { elementos. }\end{array}$ \\
\hline
\end{tabular}

(Fonte: questionários).

\section{QUADRO 4 - Posterior à peça - Os estudantes com deficiência intelectual (Cálcio e Sódio).}

\begin{tabular}{|c|c|c|}
\hline Perguntas & Respostas - Cálcio & Respostas - Sódio \\
\hline $\begin{array}{l}\text { 1) Você gostou da apresentação? } \\
\text { Conseguiu aprender algo? Escreva um } \\
\text { pouco sobre isso. }\end{array}$ & $\begin{array}{l}\text { Sim, aprendi que uma forma de } \\
\text { combater o chumbo é com coentro. }\end{array}$ & $\begin{array}{l}\text { Muito legal, aprendi que é importante } \\
\text { não entrar em contato direto com o } \\
\text { chumbo e mercúrio. }\end{array}$ \\
\hline 2) $\mathrm{O}$ que mais chamou sua atenção na & Os figurinos e os poderes. & Os poderes e as informações. \\
\hline
\end{tabular}




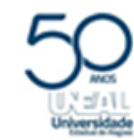

Ano 6, Vol. 6 (2), no 2. 2021, julho/dezembro de 2021. https://doi.org/10.48179/revext.v6i2.183

\begin{tabular}{|c|c|c|}
\hline ntação? & & \\
\hline $\begin{array}{l}\text { 3) Quais dos elementos apresentados na } \\
\text { peça são fundamentais para sua vida? }\end{array}$ & Cálcio, Oxigênio. & Oxigênio, se não a gente não respira. \\
\hline $\begin{array}{l}\text { 4) O que você lembra do espetáculo? Fale } \\
\text { sobre o que lembra dos elementos } \\
\text { apresentados na peça. }\end{array}$ & $\begin{array}{l}\text { Cálcio é importante para os nossos } \\
\text { ossos. }\end{array}$ & $\begin{array}{l}\text { Lembro de muitas coisas, mas o } \\
\text { sódio que falou sobre o sal e onde } \\
\text { encontrar. }\end{array}$ \\
\hline $\begin{array}{l}\text { 5) Quais desses elementos apresentados na } \\
\text { peça você lembra mais? Quais dos } \\
\text { elementos você mais gostou? Justifique } \\
\text { sua resposta. }\end{array}$ & $\begin{array}{l}\text { Gostei do Mercúrio apesar dele ser } \\
\text { um vilão, gostei da maquiagem dele } \\
\text { também. }\end{array}$ & $\begin{array}{l}\text { Gostei mais do cálcio, por ela ser a } \\
\text { inteligente da família. }\end{array}$ \\
\hline $\begin{array}{l}\text { 6) O ensino de ciências com teatro é } \\
\text { importante para aprender ciências? Você } \\
\text { consegue ver sentido nessa prática? }\end{array}$ & $\begin{array}{l}\text { Sim, gostaria de participar de algo } \\
\text { assim. }\end{array}$ & $\begin{array}{l}\text { Sim, foi muito legal de ver, vou falar } \\
\text { para professora fazer algo assim. }\end{array}$ \\
\hline
\end{tabular}

(Fonte: questionários).

Em relação aos questionários realizados, no primeiro quadro (aplicado antes da peça), demonstram um conhecimento pouco aprofundado acerca da tabela periódica. O que citaram ter aprendido sobre os elementos e os reagentes e como lidar com os sintomas causados por eles (os pesquisados: Polônio, Chumbo e Cálcio abordaram como lidar no dia a dia com os elementos) ou que aprenderam sobre família, massa, metais e gases que não se misturam com outros elementos. Ao serem questionados sobre a importância de estudar a tabela periódica, os pesquisados apontaram a importância dos elementos na vida, ao passo de identificar a necessidade de ter cuidado com os mesmos. Cálcio, sódio e chumbo responderam sobre a importância de estudar a tabela periódica. Contudo, não disseram quais seriam esses elementos. Essas afirmativas comprovam que as aulas de Ciências, mais precisamente, de Química, não potencializaram a aprendizagem da tabela periódica, pelos estudantes pesquisados.

No que se refere à pergunta 3 , questionando se aconteceram aprendizagens em Ciências a partir das Artes, dois deles citaram que não, sendo que "Polônio" complementou afirmando que seria uma forma mais divertida de aprender. Os outros dois citaram que sim, sendo que uma afirmou apenas assistir um filme. Nas respostas percebemos que na prática docente das aulas pelos alunos vivenciadas não havia metodologias diferenciadas, o que é notável ser de interesse dos alunos e de real importância para melhor construção do conhecimento. 


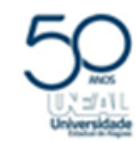

Ano 6, Vol. 6 (2), no 2. 2021, julho/dezembro de 2021. https://doi.org/10.48179/revext.v6i2.183 Sobre como foram as aulas de ciências que eles assistiram, apenas "Cálcio" citou que às vezes a professora de Biologia fazia maquete, os outros 3 afirmaram que as aulas eram com teoria, resolvendo situações químicas, muitos exercícios e uso do livro. No tocante ao conhecimento dos alunos sobre os elementos da tabela periódica em destaque na questão 6, conhecidos ou que ao menos ouviram falar, três dos quatro alunos afirmaram ouvir falar de todos e um (Chumbo), citou não ouvi falar muito deles. Nesta questão, percebemos que foi positiva a demonstração de conhecimento, pois a maioria dos alunos em algum momento conheceu algo sobre estes elementos que são os mais presentes em reações, utilizações e no cotidiano. A respeito de quais elementos eles lembram as propriedades, 3 dos alunos citaram dois elementos diferentes afirmando lembrar deles, porém, não citaram quais seriam os elementos nem as propriedades. E um deles não citou o elemento, apenas afirmou lembrar de onde eram encontrados.

Foram solicitadas sugestões para as aulas a partir da pergunta "Como as aulas de ciências poderiam ser mais atrativas?", e solicitado de apontamentos para as possibilidades de aprender ciências. Apenas um dos alunos não sugeriu, afirmando que não havia pensado sobre isso, mas, que o teatro poderia ser uma forma. Os outros três citaram entre as sugestões: paródias, desenhos, pintura e a música como possibilidade.

É possível perceber então, que nas respostas do questionário 1, anterior a peça, que as respostas demonstram certa insegurança e dificuldade ao citar os conhecimentos, ao realizar a ligação dos conteúdos ministrados com o cotidiano. Algumas respostas não foram completas em relação ao que foi solicitado, apenas dois elementos foram lembrados, as aulas foram conceituadas como resolução de exercícios.

Foi percebido, tanto por parte dos alunos com deficiência intelectual, como nos alunos de baixa visão o pensamento de que seria possível aprender ciências de uma forma diferente e não apenas com a teoria como eles mesmos citaram. Este fato valida ainda mais a percepção de que é possível e necessário que os docentes atentem para utilizar-se de metodologias diferenciadas ao se trabalhar com alunos com NEE, considerando que a diversidade existente e possível de ser criada, para possibilitar a estes alunos a apropriação dos conteúdos trabalhados.

O segundo questionário foi aplicado com os mesmos quatro alunos após a apresentação da peça teatral "Heróis e heroínas da Ciência". Observando-se as respostas, 


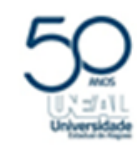

Ano 6, Vol. 6 (2), no 2. 2021, julho/dezembro de 2021.

https://doi.org/10.48179/revext.v6i2.183

sobre as impressões que ficaram da peça assistida, o que acharam interessante e se foi possível aprender. $\mathrm{O}$ os quatro estudantes afirmaram que conseguiram aprender. As justificativas demonstraram que é possível aprender química com teatro, que aprender química de uma forma diferente é atrativo, que conseguiu conhecer a função dos elementos, seus poderes e reagentes de forma diferenciada. Diante disso, percebemos que o conhecimento prévio dos alunos participantes foi potencializado a partir da experiência descrita no presente artigo.

No que se refere ao que chamou atenção na apresentação, do aluno "Nitrogênio" percebeu a produção visual, os poderes dos heróis foi o que mais chamou atenção para o aluno com deficiência intelectual, o figurino das heroínas foi que despertou sua atenção e o aluno com paralisia afirmou que os personagens chamaram a atenção, pois, "fica mais fácil aprender desta forma", que atrai a atenção os elementos serem apresentados na peça.

No tocante a relação dos elementos com o cotidiano, sobre quais são fundamentais para a vida, dois dos alunos citaram o oxigênio, afirmando que sem ele não é possível viver, "Alumínio" respondeu que o cálcio é muito importante para os ossos, e "Fósforo" disse que aprendeu que cálcio e sódio são importantes.

Ao serem questionados sobre o que se lembraram do espetáculo e o que foi apresentado dos elementos da peça, citaram a repórter sensacionalista, de quando os personagens demonstravam características dos elementos, do que fazer quando for contaminado por chumbo e também foi citado que o rubídio quando entra em contato com a água pega fogo.

Sobre o elemento que mais gostaram, foram citados: cálcio e rubídio, caracterizados como legais e que na peça é possível perceber bem quais são as propriedades de cada um; gostaram também da maquiagem que chama atenção; disseram lembrar bastante do nitrogênio, do oxigênio, do mercúrio e do cálcio; falaram sobre o alumínio que é maleável que o Hélio é presente na composição do Sol.

Sobre a última questão, na qual foi questionada a relação do ensino de Ciências com o Teatro, se é importante para aprender Ciências, os quatro alunos afirmaram que sim, justificando que há várias formas de aprender, que o conhecimento é fundamental, que tem muito sentido tudo o que está sendo apresentado e ainda sugeriram que seria interessante também incluir os jogos ou gincanas com assuntos de Ciências. 


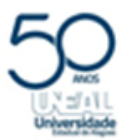

Ano 6, Vol. 6 (2), no 2. 2021, julho/dezembro de 2021.

https://doi.org/10.48179/revext.v6i2.183

O interesse dos alunos em aprender os conteúdos em Ciências de forma diferente das que já vivenciaram é evidente, e se faz necessário para ir de encontro ao ensino com ferramentas repetitivas, uso exaustivo do livro didático e construção de conceitos científicos sem a devida investigação e compreensão dos conteúdos. Cachapuz, ainda em 2005, defendeu essa ideia, por uma renovação no ensino de Ciências, de forma a buscar ao afirmar que

(...) a aprendizagem das ciências pode e deve ser também uma aventura potencializadora do espirito critico num sentido mais profundo: a aventura que supõe enfrentar problemas abertos, participar na tentativa de construção de soluções...a aventura, em definitivo, de fazer ciência. (CACHAPUZ, 2005, p.54)

Ao analisar as respostas, relacionando as falas dos alunos antes da peça teatral e após, percebemos como a apresentação chamou a atenção para os alunos em relação às possibilidades de aprender ciências de uma forma diferenciada, que é possível perceber uma maior participação uma melhor conexão entre as ideias apresentadas, a melhor aprendizagem em relação aos elementos foi constatada a partir do momento em que citaram elementos, propriedades, características, e as afirmações sobre a relação do que aprenderam com o cotidiano.

Para alunos com deficiência intelectual percebe-se que os efeitos de luz, cores e elementos visuais presentes na peça foram um diferencial junto às falas que proporcionaram a aprendizagem. Para os alunos com baixa visão, é possível citar que os efeitos de sons, luzes, e as falas enfáticas, de linguagem acessível à compreensão do público e com situações do cotidiano, envolveram os alunos com baixa visão na trama. Todas as falas reforçam a importância do trabalho realizado.

\section{CONSIDERAÇÕES FINAIS}

É responsabilidade dos educadores buscarem estratégias que visem a sanar dificuldades dos alunos e buscar estratégias diferenciadas para potencializar suas aprendizagens. O trabalho aqui descrito consistiu em investigar como a peça teatral "HERÓIS DA CIÊNCIA”, contribui ou limita a compreensão de conteúdos de Ciências da Natureza (Química), por estudantes com necessidades Educacionais Especiais (NEE). Diante dos 
Ano 6, Vol. 6 (2), no 2. 2021, julho/dezembro de 2021. https://doi.org/10.48179/revext.v6i2.183 resultados obtidos é possível considerar essa apresentação teatral se constituiu como importante ferramenta, contribuindo de forma significativa com o conhecimento dos alunos com baixa visão e deficiência intelectual, no que se refere aos elementos químicos e suas funções. A ação também contribuiu com a percepção sobre a visão dos alunos em relação às aulas de ciências, suas sugestões e conhecimentos prévios acerca do tema.

Em relação a limitar o conhecimento, foi confirmada a hipótese de não ser prática para limitar o conhecimento, consideramos que a ação acontece no envolvimento de diversos conhecimentos por se tratar de uma construção coletiva a partir da apropriação assunto a ser encenado e de demais ações que permitem o aprimoramento de habilidades na apreciação teatral. Desta forma, o trabalho com as Artes no ensino de Ciências possibilita além de outros pontos pertinentes aqui explanados, a interdisciplinaridade, defendida também que permite a construção de conhecimentos e desenvolvimentos de habilidades em diversas áreas, considerando que cada uma tem sua importância, assim, não limitando, mas, ampliando seus conhecimentos.

Vale ressaltar que a interação entre conteúdos de uma área com outra possibilita aprendizagem significativa, como bem afirma Fazenda (2011) ao dizer que a pretensão ao se trabalhar com a interdisciplinaridade não é desconsiderar a contribuição de cada ciência, e sim vem a ser uma atitude que impede o estabelecimento da supremacia de alguma ciência, em detrimento de outras.

Considerando que o questionário foi aplicado diante dos primeiros contatos com a apresentação da peça teatral, salientamos que os educandos envolvidos neste processo têm grandes possibilidades de avançar ainda mais em seus conhecimentos, de forma lúdica e sem estar apenas no espaço de referência, a sala de aula, com a continuação da ação no ambiente escolar. Vale ressaltar que na educação inclusiva os educandos devem ter possibilidade de interagir e compreender os conteúdos de forma dinâmica, diferenciada, atrativa.

Nessa pesquisa foi preciso considerar que os sujeitos envolvidos pudessem conseguir ao final de cada etapa o desenvolvimento de suas habilidades relacionadas ao seu conteúdo que aprende em sala de aula, fundamental no processo de ensino e aprendizagem de estudantes com NEE. Quando abordamos que os sujeitos precisam lidar com as evidências interligando a arte com os conceitos científicos, é preciso que as conclusões pudessem ter articulação com justificativa e coerência. Posteriormente é importante a elaboração de argumentos 


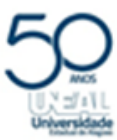

Ano 6, Vol. 6 (2), n' 2. 2021, julho/dezembro de 2021.

https://doi.org/10.48179/revext.v6i2.183

conseguindo utilizar a arte para compreensão fazendo uso da linguagem científica, tão importante quanto se utiliza de argumentos é contra argumentar, é encontrar e relacionar outros pontos de vistas.

$\mathrm{Na}$ Ciência chamamos de elaboração de conclusões ou teorias alternativas, que possam ter uma adequação ao contexto vivenciado pelo aluno. Portanto, esta produção acadêmica é importante para aqueles que se considerem sedentos por ideias que inspirem outras, no tocante a práticas que visem o melhor aprendizado de alunos e alunas com Necessidade Educacionais Especiais, tornando-se uma ferramenta de fato possível de ser realizada. Assim, é interessante para educadores e educadoras na educação especial e também no ensino regular, gestores e pessoas que se identificam com teatro, artes ou com assuntos relacionados à ciência, por contribuir com a educação que envolva a realidade daquele que aprende, seus anseios, interesses, criatividade e a exploração de suas habilidades. A exemplos: exposições tanto de poesia quanto de fotografias e outras produções os sujeitos irão fazer uso da refutação, quando será uma prática de ouvir o outro, fazer análise e relacionar com a teoria de sala de aula.

A partir deste trabalho, sugerimos a busca por outras estratégias diferenciadas para o ensino de Ciências de outras áreas do conhecimento, utilizando-se da Arte como propulsora do desenvolvimento dos educandos confirmando que o ensino de ciências possa também ser vivenciado através da arte.

\section{REFERÊNCIAS}

BARDIN, L.(2011). Análise de conteúdo. São Paulo: Edições 70.

BRASIL. Base Nacional Comum Curricular. 2018.

BRASIL. Lei $\mathrm{n}^{0} 5.692$ de 11 de agosto de 1971. Fixa as diretrizes e bases para o ensino de $1 .^{\circ}$ e $2 .^{\circ}$ graus e dá outras providências, 1971.

BORGES, M. D., Aranha, J. M., \& Sabino, J. A fotografia de natureza como instrumento para educação ambiental. Revista Ciência e Educação, 2010.

CACHAPUZ, Antônio F. ARTE E CIÊNCIA NO ENSINO DAS CIÊNCIAS. Universidade de Aveiro/CIDTFF, Portugal. NO. 31, PP. 95-106 (2014). 


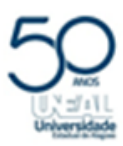

Ano 6, Vol. 6 (2), n 2. 2021, julho/dezembro de 2021.

https://doi.org/10.48179/revext.v6i2.183

CACHAPUZ, A; CARVALHO, A. M. P.; GIZ-PÉREZ, D. A necessária renovação do Ensino de Ciências. São Paulo:

Cortez, 2005.

CHASSOT, Attico. Alfabetização científica: uma possibilidade para a inclusão social, 2003. Disponível em: http://www.scielo.br/pdf/rbedu/n22/n22a09.pdf. Acesso realizado em: 02 de nov. de 2019.

FAZENDA, I. C. A. Interdisciplinaridade: Um projeto em parceria. 5 ed. São Paulo, SP: Loyola, 2002. (1991). V. 13 Coleção Educar. 119 p.

GIL, Antônio Carlos. Métodos e técnicas de pesquisa social. 5. ed. São Paulo: Atlas, 1999.

JORGENSEN, C. M. Planejando currículos inclusivos desde o início: estratégias e exemplos práticos para a sala de aula do ensino médio. In: STAINBACK, S.; STAINBACK, W. Inclusão: um guia para educadores. Porto Alegre: Artes Médicas Sul, 1999. p. 252- 287.

KRASILCHIK, Myriam. O professor e o currículo das ciências. São Paulo: E.P.U., 2012.

LEITE, B. S. Tecnologias no Ensino de Química. 1. ed. Curitiba: Appris, 2015.

MINAYO M.C.S. O Desafio do Conhecimento: pesquisa qualitativa em saúde. 11. ed. São Paulo (SP): Hucitec, 2008.

NUNES, A. S. ; Adorni, D.S . O ensino de química nas escolas da rede pública de ensino fundamental e médio do município de Itapetinga-BA: $\mathrm{O}$ olhar dos alunos.. In: Encontro Dialógico Transdisciplinar - Enditrans, 2010, Vitória da Conquista, BA. - Educação e conhecimento científico, 2010.

OLIVEIRA, M.K. História, arte e educação: a importância da arte na educação inclusiva. In: BAPTISTA, C.R.; CAIADO, K.R.M.; JESUS, D.M. Educação Especial: diálogo e pluralidade. Porto Alegre: Mediação, 2008.

PONTES et al. O Ensino de Química no Nível Médio: Um Olhar a Respeito da Motivação. XIV Encontro Nacional de Ensino de Química (XIV ENEQ). UFPR, 21 a 24 de julho de 2008. Curitiba/PR. Disponível em: < http://www.quimica.ufpr.br>. Acesso em: 10 de junho de 2019.

RANGEL, M. Ensaio sobre arte e ciência na formação de professores. Revista Entreideias, Salvador, v. 3, p. 73-86, 2014.

SARAMAgO, J. Os Poemas Possíveis. Lisboa: Editorial Caminho, 1981.

VENTURA, B.; NEVES, R. L.; RIBEIRO, V. G. P.; VALE, M. R.; GUEDES, I.; MAZZETTO, S. E. Teatro no Ensino de Química: Relato de Experiência. Rev. Virtual Quim., 2018, 


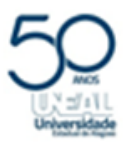

Ano 6, Vol. 6 (2), n' 2. 2021, julho/dezembro de 2021. https://doi.org/10.48179/revext.v6i2.183 10 (4), 824-840. Data de publicação na Web: 19 de julho de 2018. http://rvq.sbq.org.br/imagebank/pdf/v10n4a07.pdf

VOLPATO, G. L. Ciência: da filosofia à publicação. 6. ed. São Paulo: Cultura Acadêmica, 2013 